\title{
Comisión Nacional de Arbitraje Médico: a dos décadas de su formación
}

\author{
José Luis Sandoval-Gutiérrez
}

Servicio de Neumología, Instituto Nacional de Enfermedades Respiratorias Ismael Cosío Villegas, Ciudad de México, México

De la Fuente ${ }^{1}$ presenta un editorial sobre su experiencia personal en la formación de la Comisión Nacional de Arbitraje Médico (CONAMED). En octubre de 1996 se creó CONAMED² e inicialmente el gremio desconocía los alcances que esta comisión ofrecía; la inquietud de una actitud inquisidora por parte de los peritos podía endurecer la relación con los médicos.

La conciliación ha sido el arma para la sana resolución de los conflictos. Se enfatiza en la necesidad de mantener una adecuada comunicación en la relación médico-paciente.

La epidemiología nacional muestra que la morbimortalidad de la población ha cambiado, dando paso a las enfermedades crónico-degenerativas como causas de ingreso hospitalario y de consulta externa.

Las expectativas del paciente y de sus familiares han aumentado exponencialmente, por lo que las malas noticias y los pronósticos adversos, aceptados con serenidad en el pasado, actualmente son motivo de conflicto ${ }^{3}$.

La limitación de los recursos tecnológicos y humanos en las áreas hospitalarias, que se pueden encontrar con cierta cotidianidad sobre todo en guardias y fines de semana, son terreno fértil para la discusión y la queja.

La CONAMED ha hecho una labor de difusión y capacitación para la resolución de conflictos $^{4,5}$, permitiendo que sean las partes involucradas y no el deseo mercantil de abogados las que dialoguen sobre la conciliación menos dañina.

Es necesario que los médicos y el equipo de salud se familiaricen con las recomendaciones de esta comisión, ya que en el futuro los casos potenciales de demanda se incrementarán.

El diálogo justo, respetuoso, mesurado y empático permite continuar con la necesaria, pero a veces olvidada, relación médico-paciente.

\section{Bibliografía}

1. De la Fuente JR. La Comisión Nacional de Arbitraje Médico: 20 años. Gac Med Mex. 2016;152:726-9.

2. De la Fuente JR. Presentación de la Comisión Nacional de Arbitraje Médico. Gac Med Mex. 1996;132:357-8.

3. Recibió la Conamed 1,652 quejas por negligencia médica en 2010 (Consultado el 20 de enero de 2017.) Disponible en: http://www.jornada. unam.mx/ultimas/2013/11/19/recibio-la-conamed-1-652-quejas-por-negligencia-medica-en-2010-4360.html

4. CONAMED(Consultado el 13 de diciembre de 2017). Disponible en: https://www.gob.mx/conamed

5. Revista CONAMED. (Consultado el 23 de enero de 2017.) Disponible en: http://www.dgdi-conamed.salud.gob.mx/ojs-conamed/index.php/revconamed

\section{Correspondencia:}

José Luis Sandoval-Gutiérrez

Tlalpan, 4502

Col. Sección XV

Fecha de recepción: 29-01-2017

Fecha de aceptación: 02-02-2017

C.P. 06170 , Ciudad de México, México

E-mail: sandovalgutierrez@gmail.com
DOI://dx.doi.org/10.24875/GMM.17003243
Gac Med Mex. 2017;153:902

Contents available at PubMed www.gacetamedicademexico.com 